\title{
The alteration in peripheral neutrophils of patients with chronic kidney disease
}

\author{
Larissa Yevgenyevna Muravlyova*, Vilen Borisovich Molotov-Luchankiy, \\ Ryszhan Yemelyevna Bakirova, Anar Akylbekovna Turmukhambetova, \\ Dmitriy Anatolyevich Klyuyev, Ludmila Andreevna DemidchiK, \\ Yevgeniya Alexandrovna Kolesnikova
}

Karaganda State Medical University, Gogol Street 40, 100008 Karaganda, Kazakhstan

\begin{tabular}{l}
\hline ARTICLE INFO \\
\hline Received 07 January 2015 \\
Accepted 16 February 2015
\end{tabular}

Keywords:

neutrophils,

oxidative proteins,

histones,

neutrophils extracellular traps

chronic kidney disease.

\begin{abstract}
Recent findings have demonstrated the impaired functions of neutrophils of patients with chronic renal failure. The purpose of our research was to study oxidative modified proteins, as well as the histone spectrum in neutrophils drawn from patients with chronic kidney disease, and to estimate the ability of neutrophils to form spontaneous neutrophil extracellular traps. In this work, we have assumed that metabolic alteration in neutrophils may develop at early stages of chronic kidney disease. Materials and methods: Neutrophils obtained from patients with various stages of chronic kidney disease and degrees of chronic renal failure were used. As control, blood samples obtained from 32 healthy individuals was employed. In the examined neutrophils, advanced oxidation protein products, protein reactive carbonyl derivatives, as well as nucleosomal histones were detected. The ability of neutrophils to form spontaneous neutrophil extracellular traps was estimated. Our results have demonstrated an increase of nucleosomal histones in neutrophils of all patients with chronic kidney disease. Moreover, our work fixes the rate of growth of intracellular advanced oxidation protein products and the decreasing of protein reactive carbonyl derivatives in neutrophils from patients with chronic kidney disease. Furthermore, we demonstrate the presence of the neutrophils with altered oxidative status and the decomposition of the histone spectrum in the circulation of patients with chronic kidney disease.
\end{abstract}

The metabolic derangement in blood cells of patients with chronic kidney disease (CKD) and its possible role in CKD progression has not been clearly defined. Recent findings have demonstrated, however, the impaired functions of neutrophils in chronic renal failure (CRF). Furthermore, the lowered ability of neutrophils in uremic patients to produce hydrogen peroxide was observed [14]. Studies show that the retention of the uremic toxins ( $\mathrm{p}$-cresol and others) in the blood of uremic patients depresses the respiratory burst in neutrophils. Such findings have demonstrated that neutrophils defects may be relative to immune deficiency at CRF [14].

Current literature suggests that the neutrophils from uremic patients demonstrate higher sensitivity to Fas-mediated apoptosis. It was assumed uremic toxins could induce cellular derangement and provoke apoptosis $[5,11]$. Musal

\footnotetext{
* Corresponding author

e-mail: lem2403@mail.ru
}

$\mathrm{K}$ and Zwolinska D. [11] have also reported that neutrophils from CRF patients reveal impaired function (phagocytosis, chemotaxis, adhesion, migration and bactericidal activity).

Mayadas T. et al. [9] put forward that neutrophils can directly damage the glomerulus and may also increase the risk for autoimmunity by means of different ways: synthesis cytotoxic elements in response to inflammatory mediators, generation of autoantigenic epitopes and neutrophil extracellular traps (NETs) formation. The mechanisms by which neutrophils promote glomerulonephritis, however, need to be studied, as there is no detailed information about the metabolic status of neutrophils from CKD patients. Instead, researchers assumed that metabolic alteration in neutrophils may develop at early stages of CKD and contribute to CKD progression.

The main purpose of our research was to study oxidative modified proteins, as well as the histone spectrum in neutrophils from CKD patients, and to estimate the ability of neutrophils to form spontaneous NETs. 


\section{DESIGN OF RESEARCH}

Groups with various stages of CKD (chronic kidney disease) and degrees of CRF were created (table 1). The initial two groups included patients with CKD of 1-2 stages without CRF. The first group was made up of 38 patients with chronic pyelonephritis and CKD of 1-2 stages in the absence of a renal failure (CRF 0 ). The second group included 21 patients with chronic glomerulonephritis and CKD of 1-2 stages, also without CRF. The third and fourth groups included patients with an initial stage of CRF (CRF1) and the $3^{\text {rd }}$ stage of CKD. The $3^{\text {rd }}$ group $(n=44)$ was composed of patients with chronic pyelonephritis which were of the 3 stages of CKD and had CRF $1^{\text {st }}$ stage. Finally, the $4^{\text {th }}$ group $(\mathrm{n}=29)$ included patients with chronic glomerulonephritis and the 3 stages of CKD; the CRF of 1st stage is also included in the grouping.

All patients of the study passed the general therapeutic survey, including the main (inquiry, objective research palpation, percussion, an auscultation of internals) and an additional (measurement of blood pressure - BP, an electrocardiogram, special tests of urine by the methods of Nechiporenko and Zimnitsky) and further medical examination. Arterial pressure was determined by the standard method. Arterial hypertension was diagnosed as on the basis of the results of measurement of BP during surveys, and on the basis of a study of the anamnesis, as well as an assessment of official medical documentation (an epicrisis, protocols of inspection, including daily monitoring of the BP).

Obligatory methods of laboratory researches included the general blood and urine tests, biochemical tests of transaminase activity, and levels of creatinine and urea in blood. The assessment of glomerular filtration rate, and an indicator of the canal's reabsorption, were carried out by means of the Roeberg-Tareev's method. We also employed the research method of Kockroft and Gault (SRF CockroftGault formula). Diagnosis of chronic pyelonephritis was carried out on the basis of the criteria offered by Brenner BM [1], as well as that of Cameron JS et al. [12].

Table 1. Characteristic of study population

\begin{tabular}{|c|c|c|c|c|c|c|c|c|}
\hline $\mathrm{N}$ & Groups & $\begin{array}{c}\text { Age } \\
\text { (mean } \\
\pm \text { SD), } \\
\text { years }\end{array}$ & $\begin{array}{c}\text { Glomerular } \\
\text { filtration's } \\
\text { rate, } \\
\mathrm{ml} / \mathrm{min} \\
\end{array}$ & $\begin{array}{c}\text { Creatinine, } \\
\mathrm{mmol} / \mathrm{l}\end{array}$ & $\begin{array}{c}\text { Arterial } \\
\text { Pressure, } \\
\mathrm{mmHg}\end{array}$ & $\begin{array}{l}\mathrm{Hb}, \\
\mathrm{g} / \mathrm{L}\end{array}$ & $\begin{array}{l}\text { RBC, } \\
* 10^{12}\end{array}$ & $\begin{array}{l}\text { WBC, } \\
* 10^{9}\end{array}$ \\
\hline 1 & $\begin{array}{c}\text { Group N } 1 \\
n=38\end{array}$ & $47 \pm 5.1$ & $\begin{array}{c}98.31 \pm \\
0.12 \\
\end{array}$ & 0. & $\begin{array}{c}145.2 \pm \\
7.2 \\
\end{array}$ & $\begin{array}{c}142.3 \pm \\
1.32 \\
\end{array}$ & \begin{tabular}{|l|}
$4.3 \pm$ \\
0.11 \\
\end{tabular} & $\begin{array}{c}1.16 \\
\end{array}$ \\
\hline 2 & $\begin{array}{c}\text { Group N } 2 \\
n=21\end{array}$ & .3 & $\begin{array}{c}100.03 \pm \\
0.21\end{array}$ & $\begin{array}{c}0.065 \pm \\
0.06 \\
\end{array}$ & $\begin{array}{c}141.5 \pm \\
3.5 \\
\end{array}$ & \begin{tabular}{|c|}
$137.5 \pm$ \\
4.71 \\
\end{tabular} & \begin{tabular}{|l|}
$4.6 \pm$ \\
0.06 \\
\end{tabular} & \begin{tabular}{|c|}
$5.31 \pm$ \\
0.05 \\
\end{tabular} \\
\hline 3 & $\begin{array}{c}\text { Group N } 3 \\
n=44\end{array}$ & +5 & $\begin{array}{c}63.11 \pm \\
0.06\end{array}$ & $\begin{array}{c}0.147 \pm \\
0.03\end{array}$ & $\begin{array}{c}157.5 \pm \\
6.5\end{array}$ & $\begin{array}{c}123.4 \pm \\
7.51\end{array}$ & $\begin{array}{l}3.8 \pm \\
0.08 \\
\end{array}$ & $\begin{array}{c}6.43 \pm \\
0.42\end{array}$ \\
\hline & $\begin{array}{c}\text { Group N } 4 \\
n=29\end{array}$ & $51 \pm 6.4$ & $\begin{array}{c}56.07 \pm \\
0.12 \\
\end{array}$ & $\begin{array}{c}0.151 \pm \\
0.1\end{array}$ & $\begin{array}{c}145.4 \pm \\
5.5 \\
\end{array}$ & $\begin{array}{c}118.1 \pm \\
2.53\end{array}$ & \begin{tabular}{|l|}
$3.2 \pm$ \\
0.03 \\
\end{tabular} & \begin{tabular}{|c|}
$4.61 \pm$ \\
0.09
\end{tabular} \\
\hline
\end{tabular}

In the study, the bacteria count and active inflammatory process were diagnosed in the test patients with chronic pyelonephritis, on the basis of current bacteriological research and clinical criteria. A positive result in their urine examination was considered if the quantity of bacteria showed not less than 106 microbial bodies. In the study, the range of the microbial flora seen at HPL varied. This included Staph. aureus (57\% of all test-patients), E. coli ( $24 \%$ of total number of patients), Pseudomonas ( $2 \%$ of the total number of test-patients), Enterobacter (13\% of total number of patients) and S. saprophiticus (4\% of all test-patients).

Chronic glomerulonephritis was diagnosed on the basis of a complex clinical trial. Morphological verification by means of a nephrobiopsy was carried out on $29 \%$ of all the study patients (in two cases, IgA-deposits on the basal membranes were found. In the others - mesangial-proliferative glomerulopathy was revealed). In the clinical diagnostics of chronic glomerulonephritis, the research method recommended by the national guides to practical nephrology were used.

Glomerulopathy was diagnosed on the basis of a resistant proteinuria, as well as an erythrocyturia (hematuria), in combination with changes of SRF or without them. Thus, on the lack of clinical and laboratory symptoms of uric infection, an exacerbation of chronic pyelonephritis was taken into account.

All patients undertook ultrasonic researches of the kidneys and the other abdominal organs. The ultrasonography of kidneys revealed that in all patients with pyelonephritis, consolidation of the cup of the pelvis complex came about, and they evidenced diffusion changes of the parenchyma, and a reduction of its thickness, in comparison with the normal cross size cup of the pelvis segment. Signs of so-called 'sand' in the cups and the pelvis were seen in 9 patients. Moreover, two patients have an expansion of the cups, and microlithiasis, hence, exhibiting an acoustic shadow.

The test groups also undertook roentgenographical (X-ray) researches, wherein radioisotope renography was involved for the assessment of functions of kidneys and vascular and parenchymatousis relationships in their kidneys.

Several other specialists were involved in patient assessment: an oculist (assessment of the eye features for angiopathy and diabetic retinopathy), a neurologist (identification of symptoms of encephalopathy).

Any patients who evidenced obesity and displayed coronary heart disease with the expressed clinic of stenocardia, the existence of recently postponed myocardial infarction, brain attack or the existence of big residual changes after the postponed brain attack, were excluded from these researches - as were persons with signs of an active osteoarthropathy. Patients with competing sharp diseases or aggravations of chronic diseases in their highly active phase (activity of process of 2-3 degrees) were also excluded. Among these, were patients with pneumonia. chronic obstructive pulmonary disease, tuberculosis etc. In addition, individuals displaying accompanying autoimmune diseases in a phase of an active immune inflammation were eliminated from the study (those displaying hyperthyroidism, hypothyroidism of average and heavy degrees, rheumatoid arthritis and bronchial asthma, etc.).

Selection of patients was carried out by the doctor of medical sciences, Professor V. B. Molotov-Luchanskiy. As a control, the blood samples of 32 healthy individuals was used. 


\section{ETHICS}

The medical ethics committee of the Medical University (Karaganda) approved the study. All patients and healthy subjects received full information on probable inconveniences and complications with respect to blood sampling, before giving their consent to participate.

\section{BLOOD SAMPLING}

Blood sampling was carried out by means of a vein puncture in the morning. The blood collected from the brachial vein $(6 \mathrm{ml} / \mathrm{sample})$ was drawn into Vacutainer tubes containing heparin. For neutrophils separation, we used the procedure previously described in [4]. Cells were then washed, counted, and resuspended in buffer. The purity and viability of the obtained neutrophils were then assessed by trypan blue dye exclusion. Samples of $>85 \%$ neutrophils, with $>90 \%$ viability were obtained. The neutrophils count was done by using a Mindray BC-3200 Hematology

\section{Analyzer.}

Suspensions of neutrophils in the concentration of $10^{6}$ cells $/ \mathrm{ml}$ were lysed by freeze-thawing.

We subsequently measured the content of nucleosomal histones and histone $\mathrm{H} 1$, following the protocol of Markusheva L et al. [8]. Accordingly, lysates of neutrophils were incubated with $0.14 \mathrm{M} \mathrm{HClO}_{4}(1: 3 \mathrm{vv})$ at $0-4{ }^{\circ} \mathrm{C}$ (30 minutes) and centrifuged (10 minutes - $1100 \mathrm{~g} / \mathrm{min}$ ). Supernatants were then removed. The precipitates were resuspended with $3 \mathrm{ml}$ of $5 \% \mathrm{HClO}_{4}$. Following this action, the samples were incubated at $0-4^{\circ} \mathrm{C}$ (60 minutes) and centrifuged ( 20 minutes $-1100 \mathrm{~g} / \mathrm{min}$ ). In the resulting supernatants, the histone $\mathrm{H} 1$ fraction was detected using the spectrophotometer, Appel 303 UV. The precipitates were subsequently resuspended with $2 \mathrm{ml}$ of ethanol solution (containing 96\% ethanol, distilled water and $\mathrm{HCl})$. The samples were incubated at $0-4^{\circ} \mathrm{C}(18$ hours $)$ and centrifuged ( 10 minutes $-1100 \mathrm{~g} / \mathrm{min})$. In the obtained supernatants, the histone $\mathrm{H} 2 \mathrm{~A}, \mathrm{H} 3$ and $\mathrm{H} 4$ fractions were detected using the spectrophotometer, Appel 303 UV. The precipitates were then resuspended with $2 \mathrm{ml}$ of $0.25 \mathrm{M}$ $\mathrm{HCl}$. The samples were incubated at $0-4^{\circ} \mathrm{C}$ (18 hours) and centrifuged (10 minutes $-1100 \mathrm{~g} / \mathrm{min})$. In the resulting supernatants, the histone $\mathrm{H} 2 \mathrm{~B}$ fraction was detected using the spectrophotometer, Appel 303 UV. The ratio of histone fractions was calculated as a percentage.

The concentration of protein reactive carbonyl derivatives was detected with dinitrophenylhydrazine, following the protocol of Levine et al. [7]. Accordingly, the concentration of protein reactive carbonyl derivatives were calculated using the extinction coefficient at $370 \mathrm{~nm}=22.000$ $\mathrm{mol}^{-1} \mathrm{~cm}^{-1}[7]$. In addition, the advanced oxidation protein products (AOPP) content in neutrophil lysates was determined using the method of Witko-Sarsat et al. [15]. Furthermore, neutrophils extracellular traps were detected in the blood of CKD patients, using protocol of Dolgushin I. and Andreeva Y. [3]. Herein, $100 \mathrm{mcl}$ of whole blood samples were incubated with the $20 \mathrm{mcl}$ of the activator, pirogenal $\left(0.002 \mathrm{mcg} / \mathrm{ml}\right.$, for $30 \mathrm{~min}$, at $\left.37^{\circ} \mathrm{C}\right)$. After incubation, the blood smears were prepared on the slides. These blood smears were stained using May-Grunwald stain. NETs were detected using immersion light microscopy. The amount of NETs was estimated in percent per 100 cells.

A comparison of the results obtained was performed using the non-parametric Mann-Whitney U-test (for independent variables) and Wilcoxon matched pairs.

\section{RESULTS}

The AOPP concentration in neutrophils from patients of the $3^{\text {rd }}$ and $4^{\text {th }}$ groups was significantly higher than that in the controls, by 3.3 times and by 2 times, respectively (table 2).

Table 2. Oxidized proteins in neutrophils from CKD patients of varying severity $(\mathrm{M} \pm \mathrm{m})$.

\begin{tabular}{|l|c|c|}
\hline \multicolumn{1}{|c|}{ Groups } & AOPP. $\mu \mathrm{mol} / 10^{6}$ & $\begin{array}{c}\text { Reactive carbonyl derivatives } \\
\text { of proteins. nmoles } / 10^{6}\end{array}$ \\
\hline $\begin{array}{l}\text { Group N 1. Patients with } \\
\text { CKD 1.2 (CRF0) (with } \\
\text { chronic pyelonephritis as } \\
\text { an initial clinical form of the } \\
\text { disease) }\end{array}$ & $0.06 \pm 0.01$ & $0.06 \pm 0.01^{*}$ \\
\hline $\begin{array}{l}\text { Group N 2. Patients with } \\
\text { CKD 1.2 (CRF0) (with } \\
\text { chronic glomerulonephritis } \\
\text { as an initial clinical form of } \\
\text { the disease) }\end{array}$ & $0.06 \pm 0.01$ & $0.46 \pm 0.12^{*}$ \\
\hline $\begin{array}{l}\text { Group N 3. Patients with } \\
\text { CKD 3 (CRF1) (with chronic } \\
\text { pyelonephritis as an initial } \\
\text { clinical form of the disease) }\end{array}$ & $0.092 \pm 0.028 *$ & $0.433 \pm 0.100 *$ \\
\hline $\begin{array}{l}\text { Group N 4. Patients with } \\
\text { CKD 3 (CRF1) (with chronic } \\
\text { glomerulonephritis as an } \\
\text { initial clinical form of the } \\
\text { disease) }\end{array}$ & $0.15 \pm 0.02 *$ & $0.08 \pm 0.01^{*}$ \\
\hline Control subjects & $0.045 \pm 0.021$ & $0.908 \pm 0.143$ \\
\hline
\end{tabular}

* in comparison to control subjects $(\mathrm{p} \leq 0.05)$

At the same time, the protein reactive carbonyl derivatives concentration in neutrophils gained from the blood of patients of the 1 st and 2 nd groups was significantly lower than that in the controls, by 1.97 times and by 15 times, respectively.

Table 3. Histones proteins in in neutrophils from CKD patients of varying severity $(\mathrm{M} \pm \mathrm{m})$.

\begin{tabular}{|l|l|l|l|}
\hline \multicolumn{1}{|c|}{ Groups } & $\begin{array}{c}\mathrm{H} 1 . \\
\mathrm{mcg} / 10^{6}\end{array}$ & $\begin{array}{c}\mathrm{H} 2 \mathrm{~A} . \mathrm{H} 3 . \mathrm{H} 4 . \\
\mathrm{mcg} / 10^{6}\end{array}$ & $\begin{array}{c}\mathrm{H} 2 \mathrm{~B} . \\
\mathrm{mcg} / 10^{6}\end{array}$ \\
\hline $\begin{array}{l}\text { Group N 1. Patients } \\
\text { with CKD 1.2 (CRF0) } \\
\text { (with chronic } \\
\text { pyelonephritis as an } \\
\text { initial clinical form of } \\
\text { the disease) }\end{array}$ & $0.0091 \pm 0.0018$ & $0.1065 \pm 0.0238 *$ & $0.0241 \pm 0.0046 *$ \\
\hline $\begin{array}{l}\text { Group N 2. Patients } \\
\text { with CKD 1.2 } \\
\text { (CRF0) (with chronic } \\
\text { glomerulonephritis as } \\
\text { an initial clinical form } \\
\text { of the disease) }\end{array}$ & $0.0158 \pm 0.0013 *$ & $0.1389 \pm 0.0329 *$ & $0.0339 \pm 0.0056 *$ \\
\hline $\begin{array}{l}\text { Group N 3. Patients } \\
\text { with CKD 3 (CRF1) } \\
\text { (with chronic } \\
\text { pyelonephritis as an } \\
\text { initial clinical form of } \\
\text { the disease) }\end{array}$ & $0.0166 \pm 0.0042 *$ & $0.3239 \pm 0.2374 *$ & $0.0550 \pm 0.0339 *$ \\
\hline $\begin{array}{l}\text { Group N 4. Patients } \\
\text { with CKD 3 (CRF1) } \\
\text { (with chronic } \\
\text { glomerulonephritis as } \\
\text { an initial clinical form } \\
\text { of the disease) }\end{array}$ & $0.0072 \pm 0.0042$ & $0.0820 \pm 0.0087 *$ & $0.0183 \pm 0.0004 *$ \\
\hline Control subjects & $0.005 \pm 0.003$ & $0.0036 \pm 0.015$ & $0.005 \pm 0.002$ \\
\hline
\end{tabular}

* in comparison to control subjects $(\mathrm{p} \leq 0.05)$

In neutrophils drawn from patients of the $1^{\text {st }}$ and $2^{\text {nd }}$ groups, the H1 levels were significantly higher than that in the controls, by 1.97 times and by 1.8 times, respectively 
(table 3). The total fractions of histones H2A, H3 and H4 in neutrophils obtained from patients of the 1st and 2nd groups were also significantly higher than that in the controls, by 29.6 times and by 38.6 times, respectively. Moreover, in neutrophils drawn from patients of the 1st group, the H2B level was significantly higher than that in the controls by 4.8 times. What is more, in neutrophils obtained from patients of the $2^{\text {nd }}$ group, the $\mathrm{H} 2 \mathrm{~B}$ level was significantly higher than that in controls, by 6.78 times. When compared to the controls, in neutrophils drawn from patients of the 3rd and $4^{\text {th }}$ groups (CKD 3 and CRF1), histone H1 levels were significantly higher, at $44 \%$, and by 3.3 times, respectively.

The significantly increasing of the total fractions of histones H2A, H3 and H4 in neutrophils obtained from patients of the $3^{\text {rd }}$ group was fixed, in compared with control subjects and with the 2nd group patients. Moreover, the significantly increasing of the total fractions of histones $\mathrm{H} 2 \mathrm{~A}$, $\mathrm{H} 3$ and H4 in neutrophils drawn from patients of the $4^{\text {th }}$ group was fixed, in comparison with that of the control. At the same time, in comparison with that of the $1^{\text {st }}$ group, a tendency towards a decrease of histone total fractions was observed.

In neutrophils obtained from patients of $3^{\text {rd }}$ group (CKD 3, CRF1), histone H2B level was significantly higher, when compared with the control, and with the 1st group of patients. In addition, the significant increasing of $\mathrm{H} 2 \mathrm{~B}$ histone in neutrophils drawn from patients of the $4^{\text {th }}$ group was fixed, in compared with the control, while, in comparison with the $2^{\text {nd }}$ group of patients, the trend towards a decline of $\mathrm{H} 2 \mathrm{~B}$ histone was observed.

Finally, the formation of neutrophils extracellular traps was fixed in the blood, at $26.7 \%$ obtained from the 1 st group of patients, and, at $75 \%$ of the blood drawn from the $2^{\text {nd }}$ group of patients. Moreover, the production of neutrophils extracellular traps was fixed in the blood at $75 \%$ of the blood samples gained from the $3^{\text {rd }}$ group of patients, and at $50 \%$ of the blood samples drawn from the 4 th group patients. The total amount of NETs varied from 1 to 12 (per 100 cells).

\section{DISCUSSION}

Our results have demonstrated an increase of nucleosomal histones in neutrophils of all CKD patients. We have also fixed the rate of intracellular AOPP growth associated with CKD severity. What is more, in our study, we have shown the decreasing of protein reactive carbonyl derivatives in neutrophils being dependent on initial clinical form and severity of the CKD.

In our study, we saw that neutrophils from CKD patients exhibited increased NETs formation. This, we believe, is associated with elevated AOPP production. NETs are formed by neutrophils upon contact with various microorganisms, as well as with activated platelets or under the influence of numerous inflammatory stimuli (including reactive oxygen species) [6,16]. An increase of nucleosomal histones in neutrophils of CKD patients might, therefore, be connected with chromatin disarrangement and the releasing of nucleocomal histones from the histone core. Furthermore, elevated AOPP production might be connected with the enhanced activity of myeloperoxidase [13].
On the other hand, histones are very sensitive to reactive oxygen species, and to the reactive end-products of lipid peroxidation impact. Accumulation of oxidized histones, must, hence, decreased their ability to bind DNA. This might be the causative factor of chromatin decondensation and the increasing of nucleosomal histones in neutrophils from CKD patients.

Our work has given us opportunity to hypothesis the presence in circulation of CKD patients of neutrophils with altered oxidative status and epigenetic instability. Moreover, our data complement the existing ideas on the role of epigenetics in the mechanisms of renal disease [2].

As mentioned above, we observed the decreasing of protein reactive carbonyl derivatives in neutrophils from CKD patients. As individual proteins have different amount of carbonylation sites [10], the diminution of proteins with low capability to react with dinitrophenylhydrazine can be connected with the previous formation of oxidized proteins.

Taken together, our results demonstrate the alteration of oxidative status and histone decomposition in neutrophils from CKD patients at early stages of CRF. Further studies are under way to examine the impact of this phenomenon in the progression of CRF.

\section{REFERENCES}

1. Brenner B.M. editor (2003). Brenner and Rector's The Kidney, $7^{\text {th }}$ ed. Saunders. 2003.

2. Chmielewski M. et al.: The role of epigenetics in kidney diseases. Contributions. Sec. Biol. Med. Sci., 1, 2011.

3. Dolgushin I., Andreeva Y.: Method for detecting neutrophils extracellular traps: Patent of Russia Federation. № 2384844, 2008

4. Fedorova M., Levin V.: The complex method of study geometry. surface area. Reserve capacity of the membrane and osmotic regulation of leukocyte. Clinical medicine, 8, 2000. (Article in Russian)

5. Jaber B.L. et al.: Mechanisms of neutrophil apoptosis in uremia and relevance of the Fas (APO-1. CD95)/Fas ligand system. Journal of Leukocyte Biology, 69, 6, 2001.

6. Kirchner T. et al.: The Impact of Various Reactive Oxygen Species on the Formation of Neutrophil Extracellular Traps. Mediators of Inflammation, Article ID 849136, 2012.

7. Levine R.L. et al.: Determination of carbonyl content in oxidatively modified proteins. Method. Enzymol, 186, 1990.

8. Markusheva L. et al.: Nuclear proteins of chromatin in assessing of the effectiveness of treatment of patients with psoriasis. Clinical laboratory diagnostics, 7, 2000. (Article in Russian)

9. Mayadas T.N. et al.: Neutrophils: game changers in glomerulonephritis? Trends Mol. Med., 16(8), 2010.

10. Median A.G. et al.: Differential carbonylation of proteins as a function of in vivo oxidative stress. J Proteome Res., 2; 10(9), 2011.

11. Musal K., Zwolinska D.: Immune system in chronic renal failure patients. Adv. Clin. Exp. Med, 12, 2, 2003.

12. Davison A.M., Cameron J.S., Grunfeld J.-P., et.al. Editors (2005). Oxford Textbook of Clinical Nephrology. $3^{\text {rd }}$ Ed. New York, Oxford University Press.

13. Parker H. et al.: Myeloperoxidase associated with neutrophil extracellular traps is active and mediates bacterial killing in the presence of hydrogen peroxide. Journal of Leukocyte Biology, 91, N 3, 2012.

14. Sharma A. et al.: Impaired function of neutrophils in uraemic patients. Natl Med J India, 3, 2000.

15. Witko-Sarsat V. et al.: Advanced oxidation protein products as a novel marker of oxidative stress in uremia. Kidney Int., 49, 1996.

16. Zawrotniak M., Rapala-Kozik M.: Neutrophil extracellular traps (NETs) - formation and implications. Acta Biochim. Pol., 60, (3), 2013. 